\title{
HISTÓRIA DAS RELIGIÕES: CONCEITOS E DEBATES NA ERA CONTEMPORÂNEA
}

\author{
History of Religions: concepts and \\ debates in the contemporary age \\ Karina Kosicki Bellotti*
}

\begin{abstract}
RESUMO
O objetivo deste texto é discutir conceitos que contribuam para a delimitação de um campo de estudos da História das Religiões na era contemporânea, bem como possíveis abordagens e objetos de pesquisas sob uma perspectiva cultural. No início dos estudos de religião, no século XIX, houve a preocupação de estabelecer qual a relação entre religião e sociedade, em determinar as delimitações entre sagrado e profano; entre os aspectos racional e irracional da religião; entre suas expressões públicas e privadas. Atualmente, privilegia-se o diálogo entre essas fronteiras antagônicas e entre expressões religiosas individuais/coletivas e instâncias sociais diversas. Ao campo histórico cabe o trabalho de analisá-las, a fim de produzir um conhecimento que estimule uma visão mais ampla sobre a religião enquanto fenômeno demasiadamente humano, que permita promover diálogos e entendimentos em nossa sociedade contemporânea, tão cindida por intolerâncias, violências e preconceitos.

Palavras-chave: História das Religiões; Teoria da História; cultura; idade contemporânea.
\end{abstract}

\footnotetext{
ABSTRACT

The purpose of this article is to discuss the concepts that contributed for the delimitation of the field of History of Religion in the contemporary age, as well as the possible approaches and subjects of research under the cultural perspective. In the beginning of the religious studies in the

Professora adjunta do Departamento de História da Universidade Federal do Paraná e pós-doutora em História Cultural pela Unicamp (2011). O presente texto foi originalmente apresentado em seminário da Linha de Pesquisa Intersubjetividade e Pluralidade: reflexão e sentimento na História, do Departamento de História da UFPR, em 19 de maio de 2010.
} 
$19^{\text {th }}$ century there was the concern in establishing what was the relation between religion and society, in determining the limits between sacred and profane, the rational and the irrational aspects of religion, its public and private expressions. Lately this field has been highlighting the dialogue between these antagonistic frontiers, and between individual and collective religious manifestations and diverse social instances. I state that the historical field should analyse them in order to produce knowledge that stimulate a wider perspective on religion as a all too human phenomenon, allowing the promotion of dialogues and understandings in our contemporary society, so split by intolerance, violence, and prejudice.

Key-words: History of Religions; Theory of History; culture; contemporary age.

\section{Introdução}

Várias são as manifestações associadas à religião na era contemporânea: as feiras de exposição Expo Cristã e Expo Católica; igrejas que atraem público jovem, tais como a Bola de Neve Church (esportistas, reggaeiros, dentre outros) e a Comunidade Gólgota (para góticos); as manifestações públicas e os lobbies articulados pela Direita Cristã norte-americana, em prol da proibição do aborto; os fundamentalismos cristão, islâmico e judaico; a Teologia da Libertação e a Renovação Católica Carismática; dentre muitos outros exemplos. Os cruzamentos entre religião, mercado, violência, política, cultura, propaganda e mídia, proporcionados especialmente a partir dos séculos XIX e XX no mundo ocidental, nos fazem perguntar quais os limites da definição de religião; como os historiadores podem qualificá-la e analisá-la e partir de qual perspectiva.

O objetivo deste texto é discutir conceitos que contribuam para a delimitação de um campo de estudos da História das Religiões na era contemporânea, bem como possíveis abordagens e objetos de pesquisas sob uma perspectiva cultural. A preocupação é explorar as seguintes questões: quais os lugares das religiões na sociedade global? Qual o campo específico de atuação da História das Religiões, em meio a outras áreas de Ciências da Religião? De que forma a era contemporânea circunscreveu uma área de 
estudos das religiões e em que medida suas transformações têm ajudado a redefinir e ampliar o espectro de objetos e abordagens relativo à religião e sociedade?

Para tal, o texto divide-se em três partes: primeiramente, um histórico sobre o surgimento e a consolidação do campo de estudos da História das Religiões, impulsionado em especial pelo contexto do imperialismo e do cientificismo do século XIX, a fim de se problematizar e historicizar conceitos fundamentais - religião/religiões; cultura; primitivo/civilizado. Em seguida, os impactos sobre os fenômenos religiosos das transformações sociais e culturais em curso desde o século XIX e mais acentuadamente no século XX na sociedade ocidental e, posteriormente, global (secularização; diversidade cultural; globalização econômica e cultural); e a ampliação do espectro de conceitos e objetos - identidade/subjetividade; autonomia religiosa; competição e mercado religioso. Por fim, apresentamos alguns exemplos de estudos e abordagens culturais realizados nas pesquisas de religiões nos últimos vinte anos, a fim de explorar questões frutíferas para os estudos históricos, apontando caminhos para os sentidos do estudo das religiões nos tempos atuais.

As questões apresentadas ao longo deste texto não estão fechadas, mas apontam para caminhos que têm sido explorados por diferentes estudiosos das religiões nos últimos anos. A contribuição da comunidade acadêmica para repensá-los é fundamental e bem-vinda.

\section{Religião/religiões no século XIX-estudos inaugurais}

O estudo acadêmico e científico das religiões no Ocidente inicia-se em meados do século XIX, inaugurado pelos estudos de antropologia e etnologia do filólogo e orientalista alemão Max Müller (Lectures on the Science of Language, 1861), conhecido por criar a metodologia de religião comparada e por traduzir os Upanishads, textos sagrados da cultura hindu. Outro pesquisador contemporâneo foi o antropólogo britânico Edward 
Burnett Tylor, responsável por cunhar a teoria animista e por aplicar princípios do evolucionismo de Darwin ao estudo das culturas e das religiões ${ }^{1}$.

Nota-se que o século XIX caracterizou-se no Ocidente pelo triunfo do cientificismo, especialmente após a publicação do estudo $A$ origem das espécies (1859), de Charles Darwin, além de uma cisão aparentemente definitiva entre o sistema de pensamento religioso (judaico-cristão) e o sistema explicativo científico experimental. Tal distanciamento entre religião e ciência delineou-se aos poucos a partir de dois eventos históricos cruciais: a Reforma Protestante e o Iluminismo.

Segundo Michel de Certeau, a Reforma Protestante foi fundamental para enfraquecer o poder da religião cristã como único sistema explicativo aceito na sociedade europeia, pois estabeleceu a concorrência religiosa com a Igreja Católica, culminando nas guerras religiosas do século XVII². Se até então religião e política formavam uma só instância de poder, a partir desse período a instância religiosa rivalizará com outras instâncias sociais e políticas, além da ciência, que surge cada vez mais distanciada de elementos religiosos em suas explicações. Se na chamada revolução científica do século XVII muitos estudiosos buscavam aliar observações e experimentos a conceitos religiosos/filosóficos, explicando os mecanismos de funcionamento da "criação", no Iluminismo houve um antagonismo ferrenho entre filósofos e cientistas e a religião, seja a encarnada pelas instituições religiosas, seja a religião popular. O fim do século XVIII é palco do surgimento de novos distanciamentos em relação à religião organizada - o deísmo ${ }^{3}$ e o ateísmo, respectivamente, crença em uma inteligência divina ou Ser Supremo desvinculada de qualquer ritualismo ou dogma e a negação de Deus.

Outros eventos também contribuíram para marcar um lugar limitado para a religião no Ocidente do hemisfério Norte. A Independência Norte-Americana (1776), liderada por deístas (Thomas Jefferson, Benjamin Franklin, James Madison, George Washington, Thomas Paine), determinou

Court, 1986.

1 Ver SHARPER, Eric J. Comparative Religion: A History. 2. ed. La Salle, Illinois: Open

2 CERTEAU, Michel de. A escrita da História. Rio de Janeiro: Forense Universitária, 2002.

3 O Deísmo implica na crença em uma inteligência suprema ou ser supremo criador do Universo, com leis próprias, o que dispensaria a intervenção e a revelação divinas do cotidiano da criação. Portanto, o deísmo prescinde de uma religião institucionalizada para existir. Relatos de tal concepção religiosa existem desde o século XV, mas é somente durante o Iluminismo e sua crítica à Igreja Católica que ele ganha força política entre os intelectuais da época. 
na primeira emenda da Constituição americana a separação entre Igreja e Estado - o que não impediu que a religião (evangélica em especial) se separasse completamente da política naquele país até os dias atuais. A Revolução Francesa e o período napoleônico marcam a secularização irreversível, que inspirará as independências das colônias hispânicas nas Américas Central e do Sul. Não somente a Igreja Católica perdeu privilégios e propriedades, mas também a primazia sobre o sistema educacional.

Esses fatores ajudam a compreender as razões pelas quais o que denominamos de "religião", compreendendo a tradição ritualística, dogmática e institucional cristã (católica e protestante), perde espaço e poder na esfera pública ocidental. À luz do cientificismo, a religião torna-se um objeto de pesquisa, a ser esquadrinhado e analisado tal como qualquer outro fenômeno humano ou natural. Dessa forma, para que o estudo científico da religião surgisse, foi necessário dessacralizá- $\mathrm{la}^{4}$.

Contudo, isso não significou o completo distanciamento entre concepções religiosas tradicionais para o mundo ocidental e os procedimentos científicos no campo da antropologia e da etnologia. O Imperialismo possibilitou um grande interesse por parte de cientistas quanto a culturas consideradas "exóticas" ou "primitivas". Tal como Darwin ofereceu uma explicação científica sobre a origem das espécies para compreender o funcionamento do mundo natural, estudiosos franceses, ingleses e alemães empenharam-se em investigar as origens da espécie humana, a fim de explicar seus comportamentos e suas diferenças culturais e "raciais". O evolucionismo foi aplicado a partir da segunda metade do século XIX por cientistas sociais para caracterizar o desenvolvimento humano numa perspectiva a-histórica e atemporal.

Da mesma forma que antropólogos criminais, frenologistas e eugenistas quiseram provar as diferenças "raciais", hierarquizando diversos grupos étnicos que se tornaram conhecidos pela empresa imperialista ${ }^{6}$,

4 JULIA, Dominick. A religião: história religiosa. In: LeGOFF, J.; NORA, P. (Orgs.). História: novas abordagens. Rio de Janeiro: Jorge Zahar Editora, 1978. p. 106-131.

5 Ao longo do texto usaremos o termo "raça" entre aspas, por se tratar de uma criação humana que visou hierarquizar grupos humanos a partir de caracteres físicos diferentes. Consideramos a existência de somente uma raça - a humana (cf. AZEVEDO, Célia Maria Marinho de. Antirracismo e seus paradoxos: reflexões sobre cota racial, raça e racismo. São Paulo: Annablume, 2004).

6 Sem contar o trabalho dos "cientistas" norte-americanos, empenhados em hierarquizar indígenas, negros e caucasianos antes e depois da Guerra de Secessão (1861-1865) - cf. GOULD, Stephen J. (1981) A falsa medida do homem. 3 ed. São Paulo: Martins Fontes, 2003. 
antropólogos e etnólogos como Müller, Tylor e James Frazer ( $O$ Ramo de Ouro, 1890), partiram de premissas evolucionistas para hierarquizar os povos e suas crenças religiosas: comumente encontram-se nesses trabalhos classificações que atribuem aos povos "primitivos" o domínio da magia e aos povos "civilizados" a presença da religião institucionalizada. Povos que se atrasaram na escala evolutiva jamais poderiam alcançar o nível de organização religiosa dos povos ocidentais europeus, por estarem desprovidos de uma "verdadeira" e complexa cultura.

No século XIX, por forte influência do contexto imperialista, em que as elites letradas europeias tomam contato com diversos "Outros", surge um grande debate acadêmico sobre o conceito de cultura. Os povos primitivos não teriam cultura, por não desenvolverem instrumentos de dominação da natureza. A tradição inglesa da "cultura e civilização" definia cultura como o cultivo das faculdades humanas "superiores", possibilitada pelo desenvolvimento das artes e dos estudos científicos - ou seja, cultura seria identificada com a "alta cultura", distanciada e superior a uma suposta "baixa cultura", predominante nos meios populares como emulação grosseira da alta cultura ${ }^{7}$. Um povo que não possuísse ciência, tal como definida pelos termos europeus, não teria cultura. A religião, vista como inferior à ciência, ainda assim seria um sinal de evolução cultural se comparada com a presença de elementos "mágicos".

Grosso modo (tal debate foi muito mais complexo do que essas linhas gerais destacadas), a maioria dos estudiosos das religiões apoiou-se na busca pelas origens do sentimento ou da prática religiosa, identificando distinções entre religião e magia. Religião compreenderia uma organização social e hierárquica complexa de rituais e crenças, espelhando-se na experiência cristã europeia e norte-americana e na tradição judaico-cristã, monoteísta e patriarcal. Magia seria uma forma infantil ${ }^{8}$ e simplória de se

7 MATHEWS, G. Cultura global e identidade individual. Bauru: EDUSC, 2002. Sobre a tradição de pensamento inglesa da "Cultura e Civilização" ou "Cultura e Sociedade", ver WILLIAMS, Raymond. Cultura e Sociedade - 1780-1950. São Paulo: Companhia Editora Nacional, 1969.

8 A caracterização dos povos colonizados pelos europeus no Imperialismo frequentemente os associava a uma infantilidade intrínseca, justificando sua dominação por povos mais evoluídos ("adultos") ("Toma o fardo do homem branco/Envia o melhor de tua prole/impõe o exílio a teus filhos/para servir a necessidade do cativo/para assistir, em pesada labuta/a povos alvoroçados e incultos -/indolentes raças que acabam de conquistar/mesclar de demônio e de criança" - KIPLING, Rudyard. Fardo do homem branco, apud GOULD, S. J. Op. cit., p. 117. Ver também ARENDT, Hannah. Raça e burocracia. In: do totalitarismo. São Paulo: Cia. das Letras, 2009. p. 215-252). 
acessar a(s) divindade(s), identificadas com elementos da natureza, sem grandes hierarquizações, dependentes da figura de um líder que dominaria o contato com as entidades naturais.

Essa caracterização atemporal da evolução religiosa, que atribuiu valoração às formas religiosas dos povos "primitivos" em relação aos "civilizados", desconsiderava os fatores históricos envolvidos na relação entre crenças e práticas religiosas e suas aplicações sociais. Além disso, é preciso considerar que a categoria "magia" foi concebida no contexto religioso ocidental cristão, caracterizado de forma extremamente negativa pela Igreja Católica durante a Idade Média e a Idade Moderna, principalmente com a atuação da Inquisição. Portanto, tomar o uso deste termo tal como foi elaborado no século XIX para definir as práticas religiosas dos povos não ocidentais sem a devida problematização constitui anacronismo, além da mencionada inferiorização dos Outros não ocidentais. Entretanto, à parte das críticas feitas a essa visão sobre as religiões, seu desenvolvimento permitiu reconhecer a religião como uma instância autônoma, a ser investigada por metodologia comparativa.

Um distanciamento da lógica evolucionista foi empreendido por antropólogos como B. Malinowski e Émile Durkheim, que associavam a religião e a magia a outros aspectos sociais dos grupos pesquisados. Nas primeiras décadas do século XX, Malinoswki define cultura como um conjunto de bens e instrumentos; costumes e hábitos corporais ou intelectuais que visam à satisfação de necessidades humanas. Por isso, todos os elementos da cultura seriam funcionais, o que explica a denominação de "funcionalismo" para essa abordagem antropológica. Para este autor, toda sociedade desenvolve conhecimento científico para sobreviver à natureza; dessa forma, ciência, magia e religião estariam presentes desde os primórdios da cultura. A religião seria uma resposta à necessidade humana de enfrentar inúmeras situações de crise ao longo de sua existência individual e coletiva, em especial a morte ${ }^{10}$. A religião permitira negar a destruição pessoal trazida pela morte, conferindo sentido à morte e a outros tipos de crise, restabelecendo a coesão social e procurando apaziguar a dor.

\footnotetext{
9 MASSENZIO, M. A História das Religiões na cultura moderna. São Paulo: Hedra, 2005.

10 MASSENZIO, M. Op. cit., p. 76.
} p.74. 
Em As formas elementares da vida religiosa (1912), Durkheim constatou que os primeiros sistemas de representação do mundo eram de origem religiosa, determinando noções de tempo, espaço, número, causalidade, constituindo a "ossatura da inteligência" humana ${ }^{11}$. Ainda que considerasse as sociedades primitivas e as civilizadas como estágios da mesma história. Durkheim afastou-se do evolucionismo ao considerar a religião como instância real, que exprime sentimentos, necessidades e pensamentos reais. Assim, não haveria religiões falsas, pois todas elas seriam verdadeiras à sua maneira, respondendo a determinadas condições da vida humana.

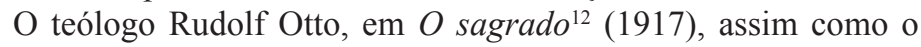
filósofo e historiador Gerardus van der Leeuw, em Fenomenologia da religião (1933), reconheceram a dimensão do sentimento e do irracional como parte explicativa da religião. Opondo-se às explicações de antropólogos e historiadores que submetiam o fenômeno religioso à razão humana, Otto e seu discípulo, van der Leeuw, romperam com o evolucionismo e o etnocentrismo ao atribuírem à categoria do sagrado a essência da religião, presente em todas as formas religiosas ${ }^{13}$. Ainda que pouco retomados na atualidade, esses autores lançaram luz sobre um aspecto fundamental da experiência religiosa, considerado em estudos mais recentes sobre as religiões - a dimensão subjetiva, nem sempre de fácil submissão às explicações racionais e funcionais, ainda mais num contexto de acentuado aumento da autonomia religiosa individual, observado ao longo do século XX.

Outro nome da fenomenologia foi o filósofo e historiador romeno Mircea Eliade, cujas obras foram bastante traduzidas para o português, tornando-o um nome bastante conhecido aos leigos e acadêmicos interessados por religião em nosso país. Suas obras mais célebres foram o Tratado de História das Religiões (1949) e O sagrado e o profano: a natureza da religião (1959), em que as categorias sagrado/profano são analisadas em diferentes culturas religiosas, chegando à constatação de que em sociedades arcaicas e tradicionais existiria uma busca pela experiência sagrada, que levaria à consagração de momentos profanos ou cotidianos; o real e autêntico

11 MASSENZIO, M. Op. cit., p. 104.

12 Para uma discussão mais aprofundada desta obra, consultar texto do Prof. Dr. Euclides Marchi para a Linha Intersubjetividade e Pluralidade, "Subjetividade do sagrado", apresentado em setembro de 2009. Disponível em: <http://br.groups.yahoo.com/group/intersub/message/75>.

13 MASSENZIO, M. Op. cit., p. 92-93. 
seria somente aquilo revestido de sacralidade e o cotidiano seria efêmero, ilusório, privado de valor. O homem histórico, das sociedades desenvolvidas, estaria dividido entre a resistência ao sagrado e a impossibilidade de renunciar a ele totalmente. Uma das questões fundamentais de Eliade foi investigar o lugar específico da religião, seja nas sociedades antigas, seja nas sociedades contemporâneas. Para isso, lançou mão do método comparativo para investigar as manifestações do sagrado - as hierofanias -, única forma pela qual ele se faria conhecer. A erudição de Eliade permite que seu/sua leitor(a) amplie profundamente seus horizontes sobre práticas e crenças religiosas.

Contudo, Eliade foi bastante criticado por outra corrente de historiadores - a chamada "Escola Italiana de Religiões"14, desenvolvida no início do século XX, paralelamente aos trabalhos de van der Leeuw e Eliade. O historiador Marcello Massenzio, em História das Religiões na cultura moderna, retomou o debate entre Raffaelle Pettazzoni e Mircea Eliade quanto ao âmbito específico da religião na sociedade. Massenzio trouxe poucas considerações sobre Eliade, apresentado à luz das críticas feitas a sua obra por Pettazzoni e Ernesto de Martino, considerados os dois expoentes da escola italiana. Para os italianos, a fenomenologia de forma geral consideraria o sagrado e o profano como um dado real das sociedades humanas, que manifestaria a essência de um "homem religioso", supostamente presente em todo ser humano ${ }^{15}$.

As considerações de Pettazzoni, elaboradas entre os anos 1920 e 1950, aproximam-se de uma abordagem histórico-cultural cada vez mais adotada no âmbito acadêmico, influenciado pela Nova História Cultural desenvolvida a partir dos anos 1970 e $1980^{16}$. Ao longo de sua obra, elaborou uma problematização complexa do conceito de religião, reconhecendo sua origem como pertencente ao contexto ocidental judaico-cristão, em especial após a cristianização iniciada durante o Império Romano. Nesse sentido,

14 A maioria dos títulos da escola italiana não está disponível em traduções para o português, nem sequer para o inglês. Muitas das ideias apresentadas nesse texto são do historiador Marcello Massenzio, também pertencente a essa escola de pensamento. Aos poucos, recentemente, algumas das obras dos historiadores italianos mais novos têm chegado ao Brasil.

15 MASSENZIO, M. Op. cit., p. 149.

16 HUNT, Lynn. Nova História Cultural. São Paulo: Martins Fontes, 1995. Ver também BELLOTTI, Karina Kosicki. Mídia, religião e História Cultural. Revista de Estudos da Religião, n. 4, 2004. 
religião caracteriza-se enquanto conceito de religação entre o ser humano e um Deus único, retirado a partir da narrativa de Gênesis da criação do mundo, do ser humano e de seu rompimento com a ordem primordial divina, e sua consequente tentativa de retomar a unidade com Deus. Aplicar esse conceito com essa acepção a experiências de outros povos não cristãos não configuraria anacronismo? Antes de se questionar sobre o lugar da religião na sociedade, Pettazzoni questionou-se sobre a própria definição de religião e a quais fatores ela estaria ligada.

Diante da pluralidade de sistemas considerados religiosos estudados até então, a escola italiana fundada por Pettazzoni defendeu o rompimento com toda visão eurocêntrica sobre religião, com o cuidado de evitar a simples compilação descritiva de crenças religiosas. O elemento fundamental para este autor foi a historicidade da experiência religiosa: "toda religião é produto histórico, culturalmente condicionado pelo contexto, e, por sua vez, capaz de condicionar o próprio contexto em que opera" ${ }^{17}$. A História de qualquer povo se opera no cotidiano, esfera elogiada e reconhecida por Pettazzoni em contraposição ao menosprezo ao cotidiano conferido por Eliade.

O âmbito da religião para o italiano estaria nos fatos extraordinários da vida (situações-limite como a caça, a guerra e a morte), mas também poderia se dar no cotidiano, no "mundo da norma", considerando o sagrado e o profano enquanto criações históricas (e não essenciais ao ser humano), que assumiriam pesos diferentes conforme contextos históricos específicos. Brevemente aplicado ao contexto atual, por exemplo, temos o exemplo das interpenetrações entre religião e mercado na sociedade global como um grande desafio para redefinir as fronteiras entre o sagrado e o profano. $\mathrm{O}$ antropólogo Lévi-Bruhl, nos anos 1910 a 1930, portanto, antes de Pettazzoni, já observara que o mundo primitivo seria fluido, não havendo distinções entre o natural e o sobrenatural, em que tudo teria um sentido "sagrado", sem o seu par antagônico "profano". Observa-se a adoção problemática do binômio sagrado/profano nos estudos sobre choques e encontros culturais entre europeus e povos não cristãos, durante o século XVI, desvelando outra questão - tal binômio também advém de uma classificação ocidental cristã.

17 MASSENZIO, M. Op. cit., p. 149. 
O que poderia resultar em um impasse para os estudos das religiões por ocidentais obtém um encaminhamento que tem inspirado a abordagem adotada em círculos acadêmicos nos últimos anos no Brasil. Afinal, se religião, sagrado, profano, magia, dentre outros conceitos, possuem origem na tradição judaico-cristã e estão enraizados em experiências históricas europeias da cristandade, é possível estudar as "religiões" de outros povos; ou o uso dessas categorias só serviria para o contexto ocidental cristão, ou, no máximo, monoteísta?

No texto Prolegômenos para a História das Religiões (1970), o historiador Angelo Brelich, discípulo de De Martino e Pettazzoni, sugeriu um procedimento que conciliasse a pluralidade das culturas com a formulação de uma chave teórica para compreender a religião. Um traço comum às manifestações religiosas conhecidas seria a crença, relativa a seres sobre-humanos historicamente determinados, que representariam aspectos vitais e humanamente ingovernáveis e que estariam suscetíveis ao controle por meio de cultos ou ritos; e/ou que possuiriam uma função protetora do grupo humano em situações extraordinárias da vida. Além da função controladora, as crenças serviriam para atribuir sentido à vida, à morte, aos seres humanos e sobre-humanos, às contingências; por meio dos ritos, os fenômenos de importância existencial estariam inseridos em um sentido cultural dentro de uma determinada ordem humana. Com isso, as crenças religiosas possibilitariam a promoção da atividade humana ${ }^{18}$.

O método usado por Brelich foi a comparação intercultural, partindo do pressuposto de que todos os povos possuiriam cultura e que tais culturas seriam interdependentes:

[...] a peculiaridade de um sistema religioso deve ser entendida, portanto, como o produto da capacidade de um determinado grupo humano de remodelar, inovar ou até mesmo de revolucionar tanto a base preexistente, que pode ser posta em relação àquilo que foi definido como "patrimônio comum", quanto ao fruto das relações, diretas ou mediadas, instauradas no curso da história com outros grupos humanos ${ }^{19}$.

18 MASSENZIO, M. Op. cit., p. 181-183. BRELICH, A. Prolegómenos a uma historia de las religiones. In: XXI, 1989.p. 30-97. Historia de las Religiones - Las Religiones Antiguas, - v. 1. 7. ed. Madrid: Siglo

19 MASSENZIO, M. Op. cit., p. 184. 
Esse tipo de visão sobre a cultura, cada vez mais aberta ao Outro não ocidental, reforça não somente uma tendência iniciada pelos estudos antropológicos críticos ao evolucionismo, mas também caminha paralela a uma valorização da diversidade cultural aberta a partir dos anos 1960 dentro e fora das academias europeias e norte-americanas, com a luta pelos direitos civis, o movimento feminista, as políticas de identidades, o multiculturalismo e os estudos pós-coloniais. O historiador Adone Agnolin afirma que o questionamento lançado pela escola italiana quanto à visão eurocêntrica e cristã predominante em parte dos estudos de religião não visou criar um desinteresse em relação ao Ocidente, mas sim repensar os valores do patrimônio cultural de forma crítica ${ }^{20}$. Acrescento: ao ampliarmos a visão sobre os conceitos relativos à religião, contemplando um contexto de diversidade cultural global, podemos repensar valores éticos e morais ocidentais e não ocidentais à luz de novos dilemas, tais como as violências de gênero, religiosas, étnicas e a discussão sobre o conceito de tolerância no âmbito religioso e secular ${ }^{21}$.

Nessa primeira seção, discutiu-se sobre os primeiros e referenciais estudos sobre religiões, que saíram do âmbito da antropologia e etnologia, dialogando com questões oriundas das relações sociais, econômicas, políticas e culturais do universo imperialista. Os focos das investigações, sejam participativas, sejam "de gabinete" (aproveitando monografias de outros estudiosos e de missionários) recaíram sobre a natureza da religião, suas origens, suas características primordiais e sua evolução; as relações entre cultura e sociedade primitiva e civilizada ( $\mathrm{e}$, consequentemente, entre religião e magia); e quais os espaços da religião na sociedade desenvolvida.

As ideias lançadas pela escola funcionalista e pela escola italiana, além do olhar sobre a subjetividade de Rudolf Otto e van der Leeuw, dão ensejo para a discussão sobre as transformações religiosas ocorridas na era

20 AGNOLIN, Adone. Prefácio. In MASSENZIO, Marcello. História das Religiões na cultura moderna. São Paulo: Hedra, 2005. p. 11-33.

21 Vale acrescentar a discussão proposta pela historiadora Christiane Lopreato sobre a ação de Desmond Tutu e o resgate do ubuntu para restaurar as relações raciais na África do Sul (cf. LOPREATO, Christina R. O outro como semelhante: alteridade Ubuntu e a reconciliação racial sul-africana" In: NAXARA, M.; MARSON, I.; BREPOHL, M. (Orgs.). Figurações do outro. Rio de Janeiro: EDUFU, 2009. p. 201-224). Sobre as interpenetrações culturais entre o mundo religioso e o secular, ver também MARTINI, Carlo Maria; ECO, Umberto. Em que creem os que não creem. Rio de Janeiro: Record, 1999. 
contemporânea, que têm gerado novas perguntas sobre o campo religioso nos séculos $\mathrm{XX}$ e $\mathrm{XXI}^{22}$.

\section{Religiões e religiosidades no século $X X$-caminhos da diversidade e da autonomia}

A secularização iniciada no século XIX na Europa e nos Estados Unidos tornou-se uma tendência amplamente acolhida por elites liberais no mundo ocidental, ainda que em ritmos diferentes. No Brasil, a separação oficial entre Igreja e Estado só ocorreu com a constituição da República, em 1891. Ainda assim, ela conseguiu manter sua influência política e cultural até meados do século XX.

Dessa forma, a secularização torna-se um fenômeno mais visível no mundo ocidental ao longo do século XX, contribuindo para uma tendência de afastamento cada vez maior entre muitos indivíduos e as instituições religiosas. Não se trata propriamente de um esfriamento da religião, ainda que tenha se confirmado em partes da Europa ocidental ao longo do século $\mathrm{XX}$, mas sim um fortalecimento da autonomia individual sobre as escolhas religiosas. Tal tendência tornou-se conhecida nos círculos americanos de estudos das religiões como "sheilismo", termo retirado de uma entrevista conduzida por pesquisadores sobre as escolhas e preferências religiosas de um determinado público norte-americano, nos anos 1990.

Ao perguntarem a uma mulher chamada Sheila sobre suas crenças religiosas, ouviram a seguinte resposta - como era ela quem dava a última palavra sobre sua vida espiritual, poderiam considerar que ela seguia na verdade o "Sheilismo"23. Essa anedota reflete uma crescente tendência no

22 Existem muitos outros pesquisadores que abordaram temas religiosos que não foram mencionados nesse texto, tais como Max Weber, Peter Berger, Marcel Mauss, que ainda são referência nos estudos sobre religiões. Esse texto não pretende esgotar a discussão sobre a historicidade do campo de pesquisas sobre religiões, mas pretende focalizar mais a produção histórica, ao menos na segunda e na terceira partes.

23 HOOVER, Stewart. M. Religion in the News: Faith and Journalism in American Public Discourse. London: Sage, 1998. 
mundo contemporâneo - o da autonomia religiosa individual, a ser exercida pelos indivíduos dentro ou fora de instituições organizadas ${ }^{24}$. No Brasil, isso se traduz tanto na porcentagem crescente de pessoas que se declaram sem religião no Censo (cerca de 7,5\% no Censo de 2000), como na prática diária de pessoas que se declaram pertencer a essa ou aquela confissão.

Outro fator que contribui para a consolidação da autonomia é a concorrência religiosa. Na sessão anterior, abordamos como tal concorrência iniciou-se com a Reforma Protestante. A partir dos séculos XIX e XX, várias correntes religiosas surgem no ocidente para fazer frente à religião institucionalizada - as correntes espiritualistas do século XIX, que sempre apelaram para a participação individual sem grandes institucionalizações (Espiritismo francês, Sociedade Teosófica, Swedenborguismo, Mesmerismo etc.); Ciência Cristã; grupos de orientação apocalíptica (Mórmons, Milleritas, Adventistas, Testemunhas de Jeová); sem contar a grande fragmentação existente dentro do protestantismo (em especial o norte-americano).

No Brasil, tal concorrência acirra-se a partir de meados do século $\mathrm{XX}$, sendo que as fileiras concorrentes à Igreja Católica posicionavam-se desde o século XIX - religiões de origem africana (candomblé, umbanda - surgida da junção entre candomblé e espiritismo kardecista), correntes protestantes (desde o século XIX) e pentecostais (desde 1910), além do espiritismo e das práticas de catolicismo popular, nem sempre sancionadas oficialmente pela Igreja Católica.

Vale acrescentar que, em nosso país, o fato de a Igreja Católica ter usufruído de exclusividade religiosa durante os períodos colonial e imperial provocou uma acomodação da cúpula católica em relação à evangelização das camadas mais pobres, maioria da população. A preocupação em educar os filhos da elite e em atuar em simbiose com o Império, pelo regime do padroado, gerou uma dupla consequência: por um lado, as expressões mais livres ou autônomas do catolicismo (catolicismo popular - um conceito complexo, pois denota uma homogeneidade que lhe escapa); por outro lado, fomentou certa indiferença em parte da população em relação a práticas religiosas, dado que para o católico era obrigatório participar dos rituais e procissões, além de cumprir o batismo, o casamento e o enterro sob a auto-

24 HOOVER, Stewart. Visual religion in media culture. In: MORGAN, D.; PROMEY, S. (Eds.). Visual Culture in American Religions. Los Angeles: University of California Press, 2001. p. 146-159. 
ridade eclesiástica ${ }^{25}$. Essa indiferença em cultivar uma vida espiritual mais engajada foi agravada pela independência religiosa trazida pelos cristãos novos no Brasil, seja pela irreligião de uns, seja pela postura crítica de outros quanto à autoridade religiosa institucional, tal como demonstrado na obra de Anita Novinsky, Os cristãos-novos na Bahia (1972).

O historiador norte-americano Andrew Chesnut afirmou que o monopólio religioso realizado pela Igreja Católica durante quase 400 anos de história na América Portuguesa resultou em uma grande margem de "católicos nominais", ou não praticantes, o que contribuiu para o crescimento de outras expressões religiosas em um contexto posterior de competição religiosa no século $\mathrm{XX}$ - mais acentuadamente dos protestantes pentecostais.

Por fim, a autonomia religiosa cresce à medida que os sujeitos dispõem de uma quantidade cada vez mais abundante de informações, opções e crenças religiosas, oferecidas pelos meios de comunicação e pelas estratégias de propaganda adotadas por diversas instâncias religiosas - instituições, grupos ou indivíduos independentes e mercado (editorial, fonográfico). A prática de se utilizar meios modernos de divulgação por parte de agentes religiosos pode ser datada da primeira impressão da Bíblia por Gutenberg, passando pela impressão e circulação da Bíblia de Lutero durante a Reforma Protestante. O próprio vocábulo "propaganda" surge no contexto religioso das disputas religiosas entre protestantismo e catolicismo nos séculos XVI e $\mathrm{XVII}^{26}$. Porém, é no contexto do protestantismo norte-americano de meados do século XIX que a apropriação de linguagem de propaganda visual e de estratégias de divulgação de massa ganha força ${ }^{27}$.

É emblemática a conclamação à renovação de linguagem feita pelo evangelista Robert F. Y. Pierce, no livro The Pictured Truth, de 1895:

Ideias regem o mundo. Essa é uma nova ideia. Aplica-se em ensinar o pensamento antigo de que a união faz a força, e traz sentidos bem conhecidos na combinação que vastamente

25 CHESNUT, R. Andrew. Competitive Spirits: Latin America's New Religious Economy. Oxford: Oxford University Press, 2003.

26 BRIGGS, Asa; BURKE, Peter. Uma história social da Mídia: de Gutenberg à internet. Rio de Janeiro: Jorge Zahar Editora, 2004.

27 MORGAN, David. Visual Piety: A History and Theory of Popular Religious Images. Los Angeles: University of California Press, 1998; MOORE, R. Laurence. Selling God in the marketplace of culture. New York/Oxford: Oxford University Press, 1994. 
multiplica o seu poder. [...] O mundo civilizado move-se rapidamente e a verdade, o Cristianismo, a sabedoria em coisas sagradas deve tomar a liderança. Essa união do pitoresco e do que é útil é um fator potente no progresso religioso, e seria uma alegria eterna introduzi-la em cada lar. E no apelo ao olhar e à audição consiste o mais alto desenvolvimento nos métodos de ensinar a verdade ${ }^{28}$.

O historiador Laurence Moore observa a sensação de que a religião cristã americana precisava se adaptar às transformações da vida moderna, bem traduzida no trecho do documento acima - "o cristianismo precisa tomar a liderança". Não somente o cientificismo tornou-se grande competidor da religião no Ocidente, mas também o mundo do espetáculo, do entretenimento e do consumo, em incipiente forma no final do século XIX em grandes e poucas metrópoles. A ponto de ministros evangélicos de diferentes orientações preocuparem-se com as diversões públicas, além de ligas femininas realizarem campanhas e cruzadas pela temperança e pelos bons costumes ${ }^{29}$.

Na virada do século XIX para o XX, aumentou o número de igrejas protestantes a utilizarem fachadas coloridas e atrativas, à moda das lojas e casas de espetáculos, para atrair a atenção dos transeuntes, emprestando um verniz moderno para sua inserção pública. Outra influência da força protestante sobre o mundo do espetáculo foi a constituição de alternativas "sadias" para toda a família, ou para moças solteiras que buscavam salas de cinema, teatro de variedades e parques para usufruir seu tempo de lazer. Moore, em instigante estudo sobre as relações entre religião e mercado nos Estados Unidos, mostrou o quanto a instância religiosa naquele país teve de se adaptar ao sucesso de seus "concorrentes", a fim de não perderem fiéis nem legitimidade pública.

O modelo norte-americano de uso de propaganda, difundido também por missionários protestantes no século XX, foi adotado por diversos países, inspirando a circulação de bens simbólicos, de cultura material de massa e de consumo, e de referências religiosas. A globalização cultural,

28 PIERCE, Robert F. Y. The Pictured Truth. Fleming H. Revell Co., 1895 (grifo nosso).

29 MOORE, R. L. Op. cit.; DEBERG, Betty. Ungodly Women (Three Indispensable Studies of American Evangelicalism). Georgia: Mercer University Press, 2000. 
acentuada a partir dos anos 1970, só contribuiu para a intensificação dessa circulação. Porém, o que exatamente circula pelos canais de divulgação midiática? As informações religiosas disponíveis nas prateleiras do "supermercado cultural" ${ }^{30}$ muitas vezes são deslocadas de seus locais de produção, perdendo em parte sua força simbólica original. Por exemplo, o uso de vários crucifixos pela cantora Madonna no início de sua carreira como utensílios de moda nos anos 1980; o uso de imagens de santos em desfiles de moda; o uso do ritmo reggae (de origem religiosa rastafári) por grupos evangélicos contemporâneos, dentre outros exemplos. Ao invés de se considerar tal tendência como um suposto desvirtuamento da simbologia religiosa, pode-se observar os diferentes sentidos de apropriação individual ou coletiva destes símbolos e discursos religiosos proporcionados pela circulação cultural.

Por outro lado, Mathews problematiza a ideia de que as escolhas dentro do supermercado cultural são livres e autônomas, pois “[...] as pessoas pegam e escolhem de acordo com sua classe, gênero, crença religiosa, etnia e cidadania, assim como de acordo com todas as exigências de sua própria formação cultural, em um supermercado cultural que faz intensa propaganda de algumas escolhas e suprime outras; elas pegam e decidem, negociando e verificando o desempenho por outras escolhas" ${ }^{\prime 31}$. Ricardo Mariano mostra como o crescimento pentecostal ocorreu no Brasil por conta do esforço evangelizador dos pentecostais em oferecer soluções pragmáticas para os problemas cotidianos ${ }^{32}$. A possibilidade de escolha de um produto no supermercado cultural é proporcional à visibilidade que ele dispõe nas suas prateleiras.

É nesse ampliado espectro de processos históricos que se deve considerar a autonomia religiosa como categoria importante da análise histórica, tomando como pressuposto de que as formas religiosas (símbolos, crenças, práticas, hierarquias, organizações) não são formas essenciais e exclusivas, mas sim criações humanas que assumem diferentes sentidos ao longo de um recorte temporal, considerando a sua historicidade como elemento fundamental para análise acadêmica. Dessa forma, a História das Religiões deve atentar não somente para a história das instituições religiosas,

30 MATHEWS, G. Op. cit., p. 57.

31 MATHEWS, G. Op. cit., p. 57.

32 MARIANO, Ricardo. Análise sociológica do crescimento pentecostal no Brasil. Tese (Doutorado em Sociologia) - FFLCH/USP, 2001 
mas também considerar que o fenômeno religioso há muito ultrapassou os muros físicos e simbólicos de tais instituições. Partindo da proposta da escola italiana de estudos da religião, utilizamos a definição de religião como um conjunto de crenças e práticas relativas a seres sobre-humanos ${ }^{33}$, na qual desmembramos os seguintes itens.

Primeiramente, ao nos referirmos à religião enquanto conjunto de crenças e práticas, consideramos dois aspectos: as crenças coletivas e individuais, e as práticas como definidoras de identidade. Conforme discussão sobre autonomia religiosa, as crenças religiosas são mantidas tanto pelas instituições religiosas, que assumem papel de autoridade e de guardiãs de dogmas, doutrinas, teologias; quanto pelos sujeitos que se apropriam de tais crenças em seu cotidiano, podendo tanto reforçar o sentido recebido por meio da tradição familiar ou institucional como retrabalhá-lo e questioná-lo, especialmente em momentos de crise e de decisão pessoal.

Em um exemplo bastante corrente em nosso país, observamos a postura oficial condenatória da Igreja Católica quanto ao uso de preservativo, expressa em comunicados de órgãos como a CNBB. E, ao mesmo tempo, milhões de mulheres que se declaram católicas desrespeitam a ordenação da Igreja, além de existir um grupo a favor do uso do preservativo e do planejamento familiar, as Católicas pelos Direito de Decidir. Ainda que não sigam a orientação da igreja, tais mulheres sentem-se católicas de uma forma ou de outra por meio de suas devoções e de outras práticas. Não cabe, portanto, a(o) historiador(a) julgar o caráter legítimo ou não de determinada crença religiosa e sua consequente prática, pois isso significaria assumir a postura da autoridade religiosa eclesiástica. A pesquisa torna-se mais enriquecida se considerarmos justamente a historicidade de tais crenças e práticas - quem as pratica? Por quê? Em que contexto? Sempre foi assim? Quais as relações de força presentes no campo religioso?

Em segundo lugar, as práticas enquanto definidoras de identidade foram analisadas pelo historiador Michel de Certeau, em A escrita da História. A partir da Reforma Protestante, o que o ajudou a definir as diferenças entre católicos e protestantes foram as práticas religiosas - não bastava crer, e sim demonstrar publicamente sua crença. As práticas tornaram-se a partir

33 SILVA, Eliane Moura; KARNAL, Leandro. O ensino religioso na escola pública do Estado de São Paulo. Volume 1: Diversidade Religiosa. São Paulo: Secretaria de Estado da Educação/UNICAMP, 2002. 
desse momento tão importantes quanto as crenças e os dogmas dentro da competição entre os cristãos europeus, perfazendo o sentimento de pertença e de identidade: "Tudo se concentra nas práticas. Através delas um grupo religioso provoca sua coesão. Nelas encontra sua âncora e sua diferença com relação a outras unidades sociais - religiosas ou não. Recebe delas uma segurança que as próprias crenças dão cada vez menos"34.

Assim, ao reconhecermos crenças e práticas relativas a seres sobre-humanos, consideramos como expressões religiosas dignas de estudo manifestações individuais (religiosidades), atuação de grupos não institucionais (organizações paraeclesiásticas, grupos de oração, grupos de estudos, correntes filosóficas/esotéricas/místicas, novos movimentos religiosos, "Nova Era" etc.); religiões institucionalizadas (catolicismo, protestantismo, budismo, islamismo, judaísmo) e suas diversas ramificações oficiais e não oficiais ao longo da História (missões, ordens, sociedades secretas); e canais de comunicação entre esses elementos (mercado de bens simbólicos religiosos, meios de comunicação, artes, política etc.).

Diante dessa ampliação dos objetos considerados passíveis de análise histórica, poderíamos nos perguntar o que constituiria prioridade na pesquisa de religiões/religiosidades? Tal ampliação não levaria a um estilhaçamento do objeto de pesquisa (religião "em migalhas")? Pergunta semelhante foi lançada aos estudos históricos pelos teóricos "pós-modernos" e pelos seus respectivos críticos e o que observamos atualmente no campo histórico é uma ampliação de objetos, temas e abordagens que destituíram as grandes narrativas com o objetivo de introduzir a diversidade de olhares e experiências históricas, a fim de deslocar a agência da História do sujeito universal eurocêntrico para outros povos e locais; para os diálogos e jogos de poder entre ocidentais e não ocidentais, entre homens e mulheres, entre adultos e crianças, entre cristãos e não cristãos, dentre tantas outras relações assimétricas que viraram objeto dos estudos históricos.

Ao questionarem os fundamentos judaico-cristãos da definição de religião, conscientizando-se da historicidade do conceito, os estudiosos das religiões deram um primeiro passo para outros questionamentos epistemológicos, o que só tem enriquecido a ciência histórica, emprestando conceitos e abordagens de outras ciências humanas, em especial da antropologia e 
da sociologia. A partir dos movimentos por direitos civis, por políticas de identidade, de gênero, de raça e pelo reconhecimento do multiculturalismo como política de diferença nos anos 1960 e 1970 nos Estados Unidos e em países da Europa Ocidental, com extensões nas Américas Central e do Sul, novas definições de cultura e de identidade surgem no âmbito acadêmico e da sociedade em geral, podendo ser incorporadas aos estudos das religiões ${ }^{35}$.

Ao analisar a centralidade do conceito de cultura na atualidade, o estudioso cultural Stuart Hall parte de duas definições: a cultura como substantiva, ou seja, como instância organizadora de atividades, instituições e relações sociais, e a cultura como categoria analítica das formas de produção do conhecimento. $\mathrm{O}$ autor constata que a maior disponibilidade e circulação de informações, propagandas e produtos culturais provocaram mudanças no cotidiano e na forma como os indivíduos definem cultura. Isto é, o lugar real da cultura refere-se à " [...] forma como a cultura penetra em cada recanto da vida social contemporânea, fazendo proliferar ambientes secundários, mediando tudo"36. Tal movimento também provoca "deslocamentos das culturas no cotidiano", isto é, reações contrárias à globalização e à homogeneização de referências culturais no cotidiano, tais como os fundamentalismos ${ }^{37}$ e nacionalismos.

A cultura, portanto, não é uma instância separada do social, mas é determinante de ações sociais, pois confere sentido às relações sociais, às subjetividades e às identidades sociais, não estando restrita à "alta" cultura, segundo a crítica feita pelo campo dos Estudos Culturais a partir dos anos 1950 e $1960^{38}$. O lugar central da cultura na sociedade globalizada da

35 No Brasil, os estudos sobre religiões estiveram mais ligados ao campo da teologia e da história confessional de instituições religiosas e ao campo da antropologia e da sociologia. Os historiadores brasileiros passam a se interessar pelo assunto mais intensamente a partir dos anos 1980 e 1990, por influência das produções da terceira geração dos Annales, conhecida como história das mentalidades ou história do imaginário, além da retomada de autores brasileiros como Sérgio Buarque de Hollanda e Gilberto Freyre. Para uma análise mais acurada do estado da arte desta historiografia, ver o artigo de Elton Nunes nesta revista.

36 HALL, Stuart. A centralidade da cultura: notas sobre as revoluções culturais do nosso tempo. In: Educação \& Realidade, Porto Alegre, v. 22, n. 2, p. 22, jul./dez. 1997 (grifo original).

37 É importante notar que os fundamentalismos religiosos são produtos do século XX, da mesma modernização que engendrou a secularização. Optamos por não abordar o fundamentalismo com maior profundidade nesse texto a fim de enfatizar um panorama mais geral dos movimentos religiosos contemporâneos.

38 HALL, Stuart. Estudos culturais: dois paradigmas. In: SOVIK, Lia (Org.). Da Diáspora: identidades e mediações culturais. Belo Horizonte: Editora UFMG; Brasília: UNESCO, 2003. p. 131-159. 
segunda metade do século XX provocou uma redefinição da cultura como categoria analítica. Assim, a cultura é considerada fluida e em eterno processo de construção ${ }^{39}$. Ao abordarmos cultura por esse prisma, lidamos com as categorias de identidade, de linguagem e de representação. Segundo o fragmento acima, a noção de cultura centra-se no entendimento de como as identidades culturais são construídas. Quais as relações entre o sujeito e a sociedade? E entre o sujeito e a tradição?

Hall parte da ideia de que a cultura não é uma questão ontológica, mas de se tornar e se recriar a partir da interpretação e do posicionamento que os sujeitos têm em relação ao seu passado pessoal, ao seu grupo e as suas circunstâncias. O sujeito define sua subjetividade perante o social e perante seu entendimento de tradição, dos conhecimentos que vem recebendo de diversas instâncias sociais. No cotidiano, o indivíduo tem a possibilidade de reproduzir e também de recriar essa "tradição", conforme diferentes necessidades.

Ou seja, não há identidades culturais fixas, mas construções feitas pelos grupos sociais para definir os papéis dos sujeitos. As identidades sociais, portanto, não são essenciais ao ser humano: não se nasce mulher, mas se aprende a ser mulher, assim como se aprende a ser homem, católico, evangélico, judeu. As identidades culturais apoiam-se em representações de papéis sociais constituídas dentro da própria cultura. Por sua vez, os sujeitos podem se ajustar a esses papéis, assim como podem rejeitá-los. Na sociedade pós-moderna, em que há múltiplos espaços de socialização, a identidade vira uma "festa móvel":

[...] o próprio processo de identificação, através do qual nos projetamos em nossas identidades culturais, tornou-se mais aberto, variável e problemático. Isto induz o sujeito pós-moderno, conceituado como isento de identidade fixa, permanente ou essencial. A identidade transformou-se numa "festa móvel": formada e transformada continuamente em relação às maneiras pelas quais somos representados e tratados nos sistemas culturais que nos circundam ${ }^{40}$.

39 HALL, Stuart. A questão multicultural. In: SOVIK, Lia (Org.). Da Diáspora..., op. cit., p.44.

40 HALL, Stuart. A questão da identidade cultural. Campinas-SP: Unicamp, 1998. (Coleção Textos Didáticos-IFCH/UNICAMP, n. 18, p. 11). 
Se a identidade não é fixa, mas constituída por meio de representações, então a linguagem desempenha uma função crucial no entendimento da cultura:

O significado surge não das coisas em $\mathrm{si}$ - a "realidade" - mas a partir dos jogos de linguagem e dos sistemas de classificação nos quais as coisas são inseridas. $\mathrm{O}$ que consideramos fatos naturais são, portanto, também fenômenos discursivos. [...] A "virada cultural" está intimamente ligada a esta nova atitude em relação à linguagem, pois a cultura não é nada mais do que a soma de diferentes sistemas de classificação e diferentes formações discursivas aos quais a língua recorre a fim de dar significado às coisas ${ }^{41}$.

Por exemplo, esse princípio vale para se compreender a religião na contemporaneidade. Por exemplo, no que se refere ao protestantismo - ainda que ele possua uma tradição de 500 anos, essa religião cristã espalhou-se pelo mundo e modificou-se em relação às Noventa e Cinco Teses de Lutero. Em trabalho nosso anterior, observamos que as culturas evangélicas circulam e são reapropriadas dentro e fora de instituições eclesiásticas: "A tradição religiosa pode ser considerada não como um conjunto estanque de práticas e crenças de igrejas, mas como um corpo doutrinário, ritualístico e histórico que se reconstrói e se repõe pela ação cotidiana de seus membros, como uma cultura em movimento e em constante negociação entre seus indivíduos"42.

Dessa forma, muito se modificou desde os primeiros estudos de religiões no século XIX - se o foco estava em definir as formas primordiais de religião e magia, ao longo do século XX as transformações sociais, políticas e culturais que levaram questionamentos à epistemologia do estudo histórico também atingiram os estudos de religião, introduzindo a primazia do indivíduo, a autonomia religiosa e a multiplicidade de expressões religiosas como variáveis a serem consideradas. Além disso, surgem novas abordagens sobre cultura e identidade, advindas do multiculturalismo e das políticas de identidade que afirmaram, nos anos 1960, que "o pessoal é político", e

41 HALL, S. A centralidade da cultura..., op. cit., 1997, p. 29.

42 BELlOTTI, K. K. Delas é o Reino dos Céus: mídia evangélica infantil e a cultura pósmoderna no Brasil (1950-2000). São Paulo: Annablume/Fapesp, 2010. 
do peso da intersubjetividade na constituição de identidades culturais. Esse tipo de postura que tem sido incorporada no Brasil pelos estudos de religião em diferentes áreas traz como questão de fundo o reconhecimento positivo das diversidades culturais e a promoção do conhecimento sobre religiões e religiosidades a fim de dissipar preconceitos e intolerâncias, tanto entre pessoas religiosas quanto entre não religiosas. Na próxima seção, seguem-se algumas questões e exemplos de abordagens que incorporam as questões discutidas acima.

\section{Abordagens, temas e objetos para o século XXI- articulando passado e presente}

Dentre os campos que se abrem nos estudos de religiões, destacamos o da Mídia, Religião e Cultura, título também de uma associação internacional que promove conferências bianuais para apresentação e discussão de trabalhos e publicação de livros. De caráter interdisciplinar, esse campo de estudos comporta pesquisas de História da Arte, Comunicação/Jornalismo, História, Sociologia e Antropologia, acerca de diferentes objetos: cultura visual religiosa, cultura visual popular religiosa, cultura material religiosa, intersecções entre cultura de massa e religiões, cobertura jornalística, mídias digitais, mercado e entretenimento, dentre muitos outros ${ }^{43}$.

A ampliação desse campo deve-se ao próprio impacto que os diferentes tipos de meios de comunicação têm exercido sobre o campo religioso mundial, seja pela introdução de uma mentalidade de propaganda e mercado no âmbito religioso, seja pelo fomento da autonomia religiosa, ou ainda pela reordenação das fronteiras religiosas operada por instituições e indivíduos no uso cotidiano de mídias tradicionais e digitais. Sem mencionar as representações e estereótipos reforçados por veículos de imprensa na cobertura jornalística de eventos de cunho religioso.

Vale notar que a religião retorna à grande imprensa internacional por meio da Revolução Islâmica de 1979, liderada pelo aiatolá Khomeini,

43 Maiores informações sobre essa área estão disponíveis no site do grupo de estudos sobre Mídia, Religião e Cultura da Universidade do Colorado em Boulder, $<$ http://cmrc.colorado.edu/ $>$. 
em oposição aberta aos Estados Unidos - a quem o líder religioso denominava de "O grande Satã". O tema do fundamentalismo religioso torna-se associado ao islamismo, sem que boa parte do mundo tenha o conhecimento histórico de que as origens do fundamentalismo estão no protestantismo norte-americano do início do século XX. Ainda que os primeiros estudos sobre o uso da mídia por grupos religiosos tenham surgido nos Estados Unidos nos anos 1950, ligados à medição de audiência, é na década de 1980 que esse campo de estudos tem um sensível aumento naquele país, ao mesmo tempo em que a Direita Cristã e os televangelistas usufruem de posição consolidada desde os anos $1970 \mathrm{em}$ parte da cultura e da sociedade americana. No Brasil, os primeiros estudos sobre mídia e religião surgem sob a ótica da Teologia da Libertação e de setores mais progressistas do protestantismo, produzindo respectivamente A Igreja eletrônica, de Hugo Assmann (1986) e Cristãos usando os meios de comunicação social: telehomilética, de Reinaldo Brose (1980).

Os anos 1990 são um período de diversificação dos estudos de mídia, religião e cultura, dos quais destacamos os trabalhos sobre cultura visual do historiador da arte David Morgan, os estudos sobre recepção e formação de sentidos conduzidos por Stewart M. Hoover e Lynn Clark e o trabalho sobre cultura material cristã desenvolvido pela historiadora Collenn McDannell.

David Morgan tem se dedicado à análise da cultura visual protestante desenvolvida nos Estados Unidos nos séculos XIX e XX, especialmente aquela produzida por artistas populares (Warner Sallman) e por entidades de evangelização (American Tract Society - Sociedade Americana de Tratados). Em uma de suas obras mais recentes, The Sacred Gaze (O olhar sagrado), seu enfoque se difere da iconografia e da iconologia por se centrar nas práticas do olhar (gaze) ao invés de focar-se nas imagens para entender seu significado. Por isso, refere-se ao olhar como um ato que alia aquele que olha (viewer), seus contemporâneos (fellow viewers), o objeto do olhar (subject of gaze), o contexto e o cenário onde se insere (context and setting of subject) e as regras que governam uma relação particular entre os que olham e o objeto ${ }^{44}$. Por essa abordagem, é possível estudar não somente a

44 MORGAN, David. Sacred Gaze: Religious Visual Cultural in Theory and Practice. Berkeley, Los Angeles, London: University of California Press, 2005. p. 3. 
relação entre a produção de arte sacra, mas também a produção e circulação de imagens na cultura de massa.

O comunicólogo Stewart M. Hoover tem conduzido pesquisas diversas na área de mídia, religião e comunicação, responsável pela fundação e liderança do Centro de Mídia, Religião e Cultura da Universidade do Colorado, em Boulder. Dentre seus trabalhos de destaque estão Religion in the News (1998), no qual analisa a abordagem jornalística de eventos religiosos nos Estados Unidos, desde a Revolução Islâmica; Electronic Giant (1979), em que analisa a atuação dos televangelistas norte-americanos; Rethinking Media, Religion, and Culture (em parceira com Knut Lundby, 1997), em que foram discutidas linhas metodológicas e teóricas sobre os estudos das religiões na contemporaneidade; e Media, Home, and Family (em parceria com Lynn Clark e Diane F. Alters, 2003), em que foram analisadas as relações entre formações e identidades religiosas diferentes e práticas de recepção de produtos de cultura de massa. Em seus estudos, observamos a preocupação em estudar os entrecruzamentos entre mercado, consumo e experiências religiosas individuais e coletivas mediadas por diversos tipos de comunicação.

A historiadora Colleen McDannell, no livro Material Christianity: Religion and Popular Culture in America (1995), inspirou vários trabalhos posteriores sobre cultura material religiosa, incluindo a cultura material de consumo de massa e o kitsch. A autora escolheu tal objeto por se tratar de um item ignorado por estudos de religiões. Para ela, os estudos teológicos e acadêmicos enfatizariam a cultura letrada como repositório da religião, enquanto que expressões religiosas populares, dentre as quais a cultura material e visual, eram relegadas ao segundo plano, por não serem consideradas instâncias religiosas legítimas pela cultura religiosa letrada - sendo também associadas a grupos iletrados, mulheres, crianças, imigrantes.

No capítulo sobre Comércio cristão - "Christian Retailing", McDannell faz uma análise da história e dos sentidos de produtos feitos para o público evangélico norte-americano. Das origens vitorianas, de 1840 a 1900, em que artigos com imagens e frases religiosas eram produzidos por grandes companhias, até o advento das livrarias cristãs ("Christian Bookstores") e a profissionalização do comércio cristão, McDannell observa que os evangélicos norte-americanos depositaram sentidos e práticas não somente em imagens, mas também em objetos, fortalecendo a chamada 
cultura evangélica ao mesmo tempo em que se fortaleciam como mercado consumidor e força política na sociedade americana:

\begin{abstract}
O comércio cristão providencia as imagens visíveis e táteis que ajudaram protestantes conservadores a criar uma subcultura cristã. Um dos efeitos dos movimentos de direitos de minorias nos anos 1960 e 1970 foi a ênfase na importância de comunidades de indivíduos com as mesmas afinidades. A comunidade era criada não somente pelo compartilhamento de ideais e objetivos, mas também pelo uso de camisetas com slogans políticos, pela exibição de arte apropriada, pela apreciação de certos tipos de música. [...] O comércio cristão, assim como as escolas e terapeutas cristãos, é uma outra forma de tentativa de criar uma cultura religiosa paralela à cultura secular americana ${ }^{45}$.
\end{abstract}

Objetos considerados por intelectuais como kitsch, aparentemente sem valor estético artístico, entram nessa lógica como objetos de recordação, de celebração e de identificação, como defendeu McDannell ${ }^{46}$. O cotidiano é considerado de forma semelhante à de Raffaelle Pettazzoni - como o espaço formativo da identidade religiosa individual e coletiva:

Como David Morgan acertadamente enfatizou, o dia a dia foi subestimado como um aspecto que ajuda a moldar a identidade pessoal e institucional, mas que pode assumir um papel mais formativo que os mais raros "ritos sagrados e eventos dramáticos". O que os crentes fazem repetidamente não somente reforça suas percepções de realidade, como também vem a constituir sua realidade ${ }^{47}$.

Outro campo em expansão é o que se dedica às relações entre gênero e religião, atentando para os papéis de gênero consagrados a homens e mu-

45 McDANNELL, Colleen. Material Christianity, Religion and Popular Culture in America. New Haven, Connecticut: Yale University Press, 1995. p. 267s.

46 McDANNELL, Colleen. Op. cit., p.163-197.

47 HANGEN, Tona J. Redeeming the dial: Radio, religion and Popular Culture in America. Chapel Hill, NC: University of North Carolina Press, 2002. p. 17. 
lheres nas cosmogonias e narrativas religiosas e suas respectivas aplicações no cotidiano religioso e secular. Além disso, os pesquisadores dessa área têm analisado os jogos de poder dentro de instituições religiosas (a proibição de ordenação de pastoras em algumas denominações evangélicas; o impedimento de exercer cargos de poder na Igreja Católica, em contraste com a maioria numérica da membresia feminina; o desenvolvimento de poderes paralelos e alternativos femininos etc. ${ }^{48}$. Vale notar que a concepção de papéis de gêneros na sociedade ocidental está profundamente arraigada na tradição patriarcal judaico-cristã, que estabelece o homem enquanto criação à imagem e semelhança de Deus, sendo a mulher a imagem secundária e derivada do homem, justificando posteriores violências simbólicas e físicas que se repetem até os dias atuais ${ }^{49}$. Nesse sentido, teólogas feministas reelaboram a hermenêutica bíblica a fim de desvelar as leituras e traduções patriarcais contidas em diferentes versões bíblicas.

Além disso, outros temas têm sido contemplados pelos estudiosos das religiões - não necessariamente historiadores: diálogos inter-religiosos e movimentos ecumênicos; as intersecções entre religião e política; trânsitos religiosos; perspectivas transnacionais na circulação de ideias e práticas religiosas (ocidente-oriente; hemisfério norte-sul).

Uma questão que tem recebido nossa atenção em pesquisas recentes é a das fronteiras entre religião, mercado e entretenimento. Por exemplo, nosso atual projeto, Desfrutando a vida diária: a cultura do bem-estar e da juventude na mídia evangélica no Brasil (anos 1980 a 2000), tem como objetivo analisar, sob a perspectiva da História Cultural, os discursos sobre o bem-estar físico, material e emocional nos produtos de mídia evangélica em circulação no Brasil das décadas de 1980 a 2000, tema pouco explorado nos estudos de protestantismo, apesar da sua popularidade crescente. Pretendemos focalizar os discursos e produtos referentes ao bem-estar

48 Para aprofundamento na área de gênero e religião, conferir os trabalhos das sociólogas Sandra Duarte de Souza (Umesp) e Maria José Rosado Nunes (PUC-SP), da historiadora Eliane Moura da Silva, da teóloga Ivone Gebara e a Revista Mandrágora, do Núcleo de Estudos Teológicos da Mulher na América Latina (NETMAL), disponível em: $<$ http://www.metodista.br/ppc/netmal-in-revista/ppc/netmal-in-revista/netma101/apresentacao>. Cf. SOUZA, Sandra Duarte de. Revista Mandrágora: Gênero e Religião nos Estudos Feministas. Estudos Feministas. Florianópolis, v. 12, n.e., p. 122-130, setembro-dezembro de 2004.

49 SOUZA, Sandra Duarte de (Org.). Gênero e religião no Brasil: ensaios feministas. São Paulo: Metodista, 2006. 
físico, material e emocional produzidos por autores evangélicos brasileiros e americanos de grande circulação no Brasil, tais como Silas Malafaia e Joyce Meyer, além de produtos e serviços disponíveis no crescente mercado evangélico, enfatizando em especial o público jovem (15 a 29 anos). Além disso, por meio dessas fontes, analisaremos como a autonomia religiosa é fomentada por esses ministérios e como essa mídia ensina os evangélicos a viverem bem no "mundo", sem fazerem parte dele.

Nessa perspectiva, quando se tem constituído um mercado religioso competitivo em nosso país, de que forma podemos analisar fenômenos como o engajamento de jovens em igrejas novas, como a Bola de Neve Church, ou em movimentos de juventude cada vez mais expansivos em igrejas tradicionais, como a Assembleia de Deus? Ou então, quando ocorrem fenômenos como a Cristoteca, um misto de discoteca e missa católica, em que bandas gospel evangélicas tocam após a comunhão, como lançar uma olhar histórico crítico? O que essas expressões dizem sobre religião e sociedade na era contemporânea?

O olhar religioso institucional cristão, tanto do lado católico quanto do protestante, tende muitas vezes a condenar tais expressões, tratando-as como desvirtuamento de ritos tradicionais. No que se refere a eventos como a Expo Cristã e a Expo Católica, feiras de exposições de São Paulo-SP em que empresas de diferentes artigos religiosos expõem seus produtos para lideranças, eclesiásticos e o público em geral, há os que evocam o episódio bíblico do Novo Testamento, em que Jesus Cristo expulsa os "vendilhões do templo" 50 , para condená-los. Porém, como historiadores da religião, que explicações podemos oferecer sobre os sentidos dessas práticas - seriam religiosas, mercadológicas, falsas, autênticas? Aos olhos de quem? Seriam uma forma de mercantilização da fé ou mundanização do sagrado? $\mathrm{Ou}$ sacralização do mercado?

Para os historiadores, é importante se perguntar a quem interessa manter as fronteiras entre religião, mercado e entretenimento e a quem interessa misturá-las. No discurso de lojistas e produtores de artigos cristãos, encontramos a junção entre fé e mercado - por meio da produção de cadernos com mensagens bíblicas, camisetas e música gospel, bonecos de

50 "Dai, pois, a César o que é de César e a Deus o que é de Deus." (Lucas 20.25). Bíblia na versão Almeida, revista e atualizada. 
Esther, Golias e Jesus, bíblias de capas modernas para os adolescentes, dentre muitos outros itens, tais empresários e comerciantes alegam sacralizar o mercado, investindo sua profissão de sentido missionário.

Por outro lado, os artigos mais populares são bastante pirateados, comprados por fiéis católicos e evangélicos, trazendo outro elemento interessante para a pesquisa - ainda que produtores, pastores e padres demonizem a pirataria, enquanto prática ilegal e pecado, muitos fiéis apegam-se à autonomia religiosa e ao direito de escolha do consumidor. Observamos, portanto, que o estabelecimento de fronteiras entre sagrado e profano, entre religião e mercado, deve ser considerado pelos historiadores como uma prática fluida, que envolve diversos agentes em luta para definir sentidos verdadeiros e autênticos de sua crença religiosa, em detrimento dos seus concorrentes. Isso significa que as fronteiras que procuravam isolar religião de outras instâncias sociais estão cada vez mais móveis e permeáveis à medida que o foco da autoridade religiosa institucional compete com a primazia do indivíduo.

A contribuição da disciplina histórica na construção de um campo específico de estudos das religiões e religiosidades passa por instrumentos e questionamentos desenvolvidos pela ciência histórica nos últimos anos, seja sob influência da Nova História, seja pelos "Pais Fundadores" dos Annales, seja pela "virada linguística": estabelecer comparações (continuidades e descontinuidades) entre fenômenos presentes e possíveis correspondentes do passado e suas diferentes temporalidades; e buscar a historicidade dos discursos, práticas, crenças e agentes religiosos, tendo em vista certas ferramentas conceituais na relação entre sociedade e indivíduos sob uma perspectiva cultural.

No início dos estudos de religião, houve a preocupação de estabelecer qual a relação entre religião e sociedade, em determinar as delimitações entre sagrado e profano, entre o aspecto racional e irracional da religião, entre suas expressões públicas e privadas. Atualmente, privilegia-se o diálogo entre essas fronteiras antagônicas e entre expressões religiosas individuais/ coletivas e instâncias sociais diversas, tendo em mente o ensinamento de Durkheim de que todas as religiões são verdadeiras porque cada uma produz a sua verdade. A nós, historiadores e historiadoras, cabe o trabalho de analisá-las a fim de produzir um conhecimento que estimule uma visão mais ampla sobre a religião enquanto fenômeno demasiadamente huma- 
no, que permita promover diálogos e entendimentos em nossa sociedade contemporânea, tão cindida por intolerâncias, violências e preconceitos.

Recebido em fevereiro de 2011. Aprovado em março de 2011. 